\title{
Primary osteosarcoma of the breast: a case report
}

\author{
Chan Seok Yoon, Sung Soo Kang \\ Department of Surgery, Cheil General Hospital and Women's Healthcare Center, Dankook University College of Medicine, Seoul, \\ Korea
}

Primary osteosarcomas of the breast are extremely uncommon. Here we describe a case of a 77-year-old woman who presented with a hard mass on her right breast. Mammography and breast ultrasound demonstrated a round-shaped calcified mass on the right breast but the features were not definitely diagnostic. For diagnostic purposes, an excisional biopsy was performed and the mass proved to be a primary osteosarcoma of the breast by pathologic findings. PET-CT and whole body bone scan showed neither evidence of metastasis nor underlying bone lesions. Wide excision without axillary lymph node dissection was performed after diagnosis. Further treatment such as adjuvant chemotherapy or radiation therapy was not performed. We discuss proper treatment of this rare type of breast cancer.

[Ann Surg Treat Res 2017;93(1):57-60]

Key Words: Osteosarcoma, Breast, Local excision

\section{INTRODUCTION}

Nonepithelial malignancies of the breast are known to be less than $1 \%$ of breast tumors with the most common being malignant phyllodes tumor, which accounted for $61 \%$ of these diagnoses [1]. Osteosarcomas represent $12.5 \%$ of all breast sarcomas with only 50 cases of primary osteosarcoma reported in the literature in the past 38 years, between 1957 and 1995 (median age, 64.5 years) [2,3]. Published references are generally limited so herein we report clinical and histopathological features of primary osteosarcoma of the breast.

\section{CASE REPORT}

A 77-year-old woman with past medical history significant only for diabetes mellitus presented with a palpable breast mass to Cheil General Hospital and Women's Healthcare Center in December 2016. She said the mass had been palpable for 4 months and was growing fast. She did not feel pain nor had nipple discharge. On clinical examination, a hard and movable mass with well-circumscribed margins of about $4 \mathrm{~cm}$ in diameter was present on the right upper breast. On mammography, a calcified mass with well-defined margins on the right upper breast was found (Fig. 1). Breast ultrasound examination revealed a well-circumscribed hypoechoic right breast mass measuring $2.3 \mathrm{~cm}$ in diameter with calcifications and posterior shadowing at 'one o'clock' (Fig. 2). An excisional biopsy was performed. The mass proved to be a primary osteosarcoma by pathologic findings including immunohistochemistry results.

On gross examination, there were three fragments of the right breast measuring $3.5 \mathrm{~cm}, 2.5 \mathrm{~cm}$, and $1 \mathrm{~cm}$ in size. The cut surfaces showed variegated solid masses, with diffusely scattered calcifications. The tumor margin was relatively demarcated.

Microscopic examination revealed that the malignant tumor exhibited abundant neoplastic bone formation that was intimately admixed with malignant tumor cells (Fig. 3A). Characteristically, the neoplastic bone had a woven shape and was comprised of eosinophilic osteoid and irregular
Received March 17, 2017, Revised April 7, 2017, Accepted April 25, 2017

\section{Corresponding Author: Sung Soo Kang}

Department of Surgery, Cheil General Hospital and Women's Healthcare Center, Dankook University College of Medicine, 17 Seoae-ro 1 gil, Junggu, Seoul 04619, Korea

Tel: +82-2-2000-7276, Fax: +82-2-2000-7791

E-mail: breastkang@gmail.com
Copyright (C) 2017, the Korean Surgical Society

(c) Annals of Surgical Treatment and Research is an Open Access Journal. All articles are distributed under the terms of the Creative Commons Attribution NonCommercial License (http://creativecommons.org/licenses/by-nc/4.0/) which permits unrestricted non-commercial use, distribution, and reproduction in any medium, provided the original work is properly cited. 


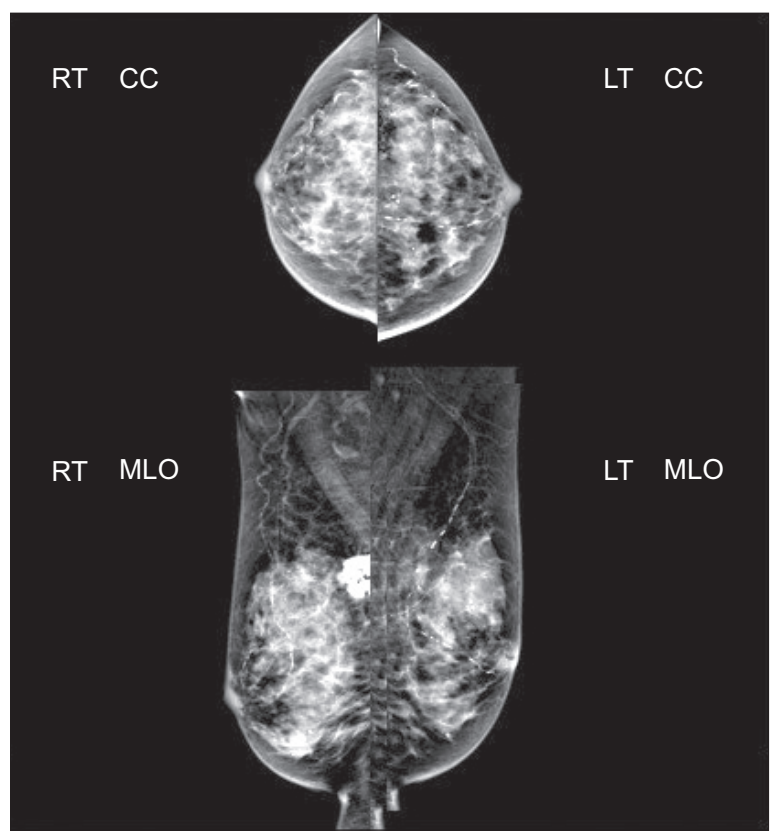

Fig. 1. Mammography on both breasts. A 2-cm-sized calcified mass on right upper deep portion. RT, right; LT, left; CC, craniocaudal view; MLO, mediolateral oblique view.

amorphous trabeculae, which included the tumor cells (Fig 3B). Bone calcification was present or absent. In the present case, the tumor cells were highly pleomorphic and anaplastic having hyperchormatic nuclei, conspicuous nucleoli, and abundant eosinophilic cytoplasm. Among them, some tumor cells were composed of plasmacytoid and spindled cells. Among histological variants, this tumor showed differentiation from osteoblastic and osteoclastic (giant, cell-rich) subtypes (Fig. 3C-E). Mitotic figures were frequently seen. The tumor margin showed focal infiltrative growth (Fig. 3F). On immunohistochemistry, the tumor cells were focal positive for smooth muscle actin, and were negative for cytokeratin, s-100 protein, and $\mathrm{CD} 31$.

After excisional biopsy, breast MRI, PET-CT, and whole body bone scan were performed to detect metastasis or underlying lesions (Figs. 4, 5). However, there was no evidence of chest wall invasion or metastasis. The lack of bone lesions on whole body bone scan and PET-CT supported the diagnosis of primary osteosarcoma of the breast. Wide excision without axillary node dissection was performed after diagnosis and the surgical resection margin was tumor free. We did not recommend adjuvant chemotherapy nor radiation therapy. This patient is under regular follow-up without further treatment and she remains well for 3 months, without tumor recurrence.

\section{DISCUSSION}

Less than 150 cases of primary osteosarcoma of the breast

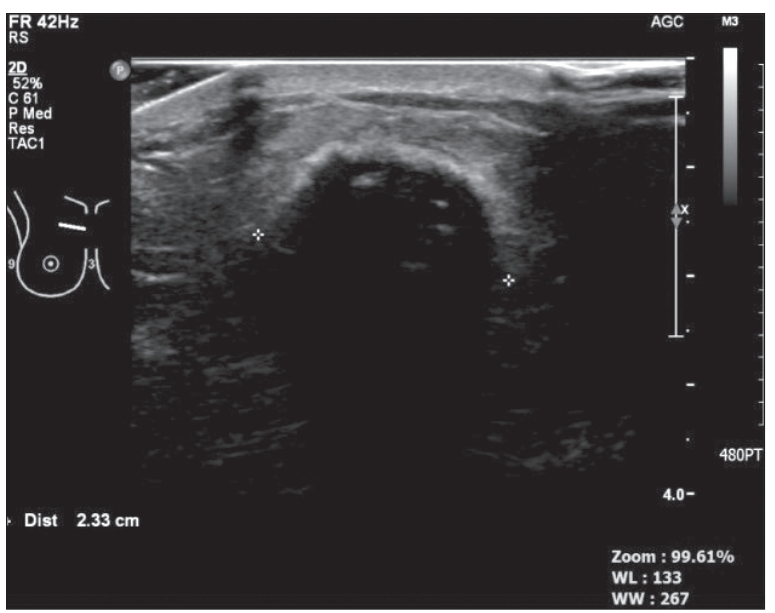

Fig. 2. About 2.3-cm-sized calcified low echoic mass with posterior acoustic shadowing was noted at $1 \mathrm{o}^{\prime}$ clock in right upper breast on breast ultrasound.

have been reported in the literature [2-4]. Primary osteosarcoma has been expressed as one of the matrix-producing metaplastic breast malignancies [5]. There has been difficulty in distinguishing metaplastic neoplasm from phyllodes tumor in some cases [5-7].

The majority of the cases are in patients that are over 60 years old with a reported median age of 64.5 years [3]. Main symptoms include pain and the presence of a growing palpable breast mass that is typically movable, hard, and irregular without axillary lymphadenopathy. These are not specific findings but common for breast neoplasms. In some cases, a rapid growing mass on the breast is shown [3,8]. Prognosis is generally poor with an overall 5-year survival of 38\% reported according to a 50-case report. The most common metastatic site is the lung followed by bone. Among 39 patients, 11 patients recurred locally and 15 patients had metastatic lesions at a mean 12.1 months [3].

As for mammography at diagnosis, the findings like coarse, speckled microcalcifications with an irregular or lobulated mass are approximately $67 \%$ and benign looking findings like fibroadenoma are 33\% [3]. There can be no calcifications on some case [9]. If the mass is calcified, excisional biopsy would be preferred over core needle biopsy because of the hardness of the mass. For detection of local invasion and metastatic lesions, Breast MRI, whole body bone scan, and PET-CT are performed (Figs. 4, 5). The fact of no other bone lesions supported the diagnosis of primary osteosarcoma of the breast addition to pathologic diagnosis.

Complete surgical removal of the tumor should be done as initial treatment. Even though there are no current treatment guidelines due to limited data, most authors suggest that surgical excision or mastectomy with adequate margins as a standard of therapy for breast sarcoma $[2,3,8]$. In osteosarcoma, 

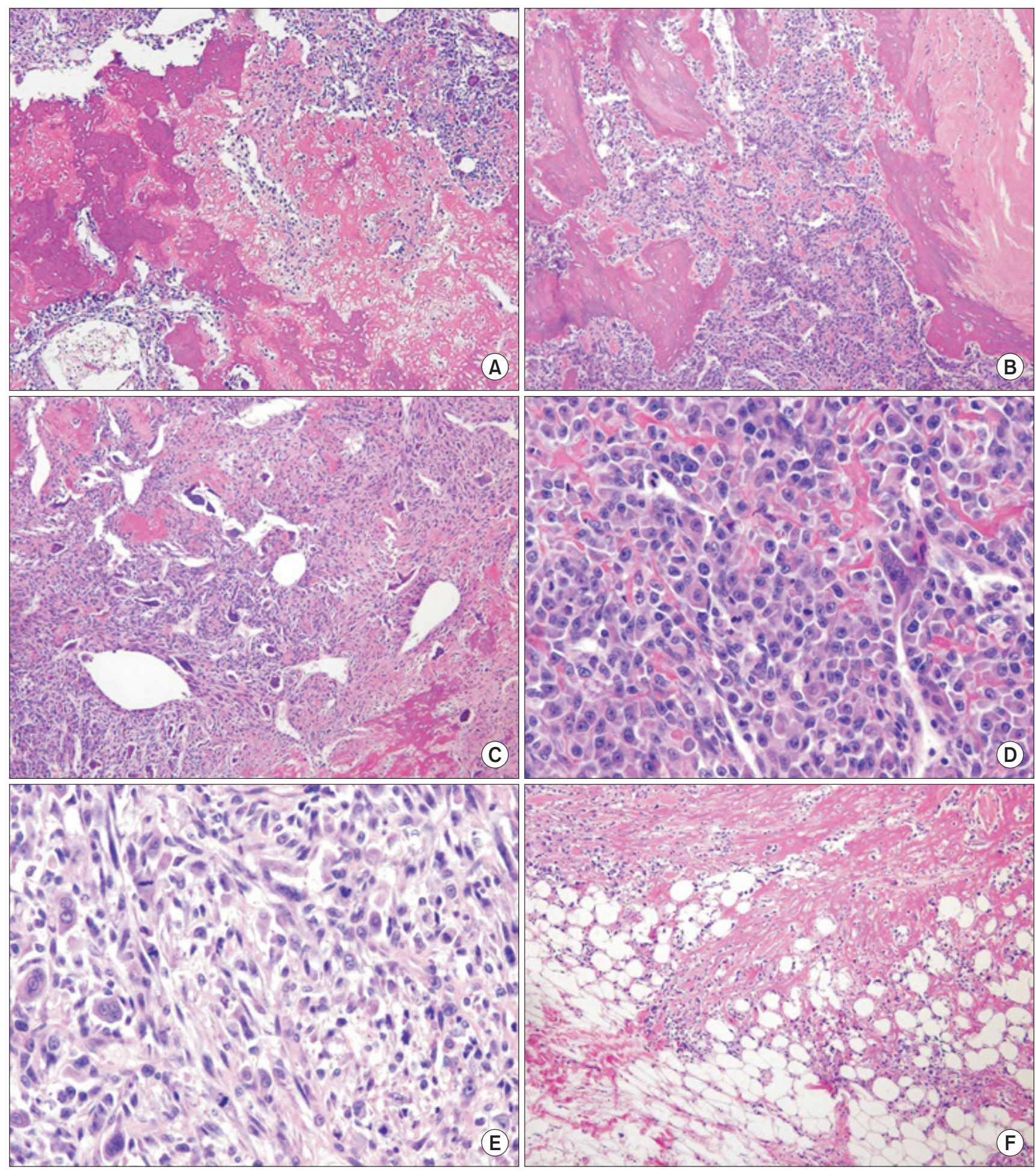

Fig. 3. (A) Malignant tumor shows neoplastic bone composed of calcification with osteoid (left) and irregular trabeculae having tumor cells (right). Malignant osteoid bone intimately associated with tumor cells (H\&E, $\times 100)$. (B) Neoplastic bone is intimately admixed with malignant tumor cells $(\mathrm{H} \& \mathrm{E}, \times 100)$. (C) Tumor cells are composed of highly pleomorphic stromal cells (left) and spindle cells (right). Main histological variants are osteoblastic and osteoclastic (giant, cell-rich) subtypes $(\mathrm{H} \& \mathrm{E}, \times 100)$. (D) Plasmacytoid sarcoma cells have hyperchormatic nuclei, conspicuous nucleoli and abundant eosinophilic cytoplasm, with frequent mitoses $(\mathrm{H} \& \mathrm{E}, \times 400)$. (E) Spindle cell sarcoma shows pleomorphic stromal cells and frequent mitoses $(\mathrm{H} \& \mathrm{E}, \times 400)$. (F) The tumor margin reveals partly infiltrative growth $(\mathrm{H} \& \mathrm{E}, \times 100)$. 


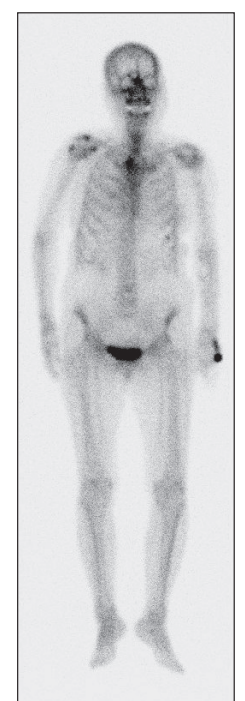

Fig. 4. No evidence of bone metastasis, no underlying bone lesion on whole body bone scan. Postexcision state.

hematogenous spread is more common than lymphatic spread. According to an analysis of 50 cases, 20 cases received axillary node evaluation while the others did not. There was no positive axillary node on all axillary nodes [3]. In general, axillary node dissection is not considered in surgery.

The effect of systemic treatment is not established yet. Extraskeletal sarcoma seems to be less responsive than skeletal osteosarcoma, though some authors state positive benefits of chemotherapy $[5,10]$. Otherwise, it is unclear whether radiotherapy is an effective treatment or not. In cases of positive

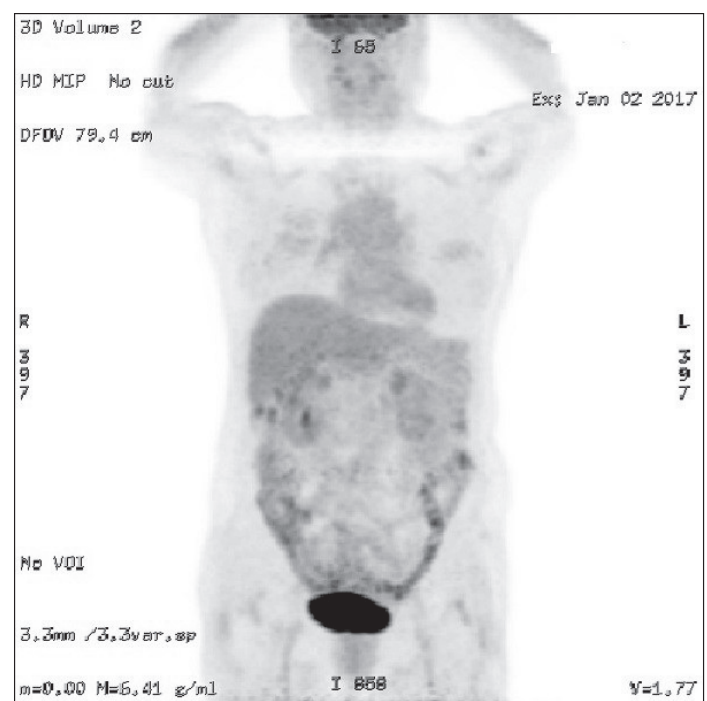

Fig. 5. No evidence of distant metastasis, no underlying bone lesion on PET-CT. Postexcision state.

margin after surgery or a huge mass that cannot be excised well, radiotherapy may be performed. Thus, the treatment plan should be considered carefully according to patient status. In future, more cases will help construe proper treatment.

\section{CONFLICTS OF INTEREST}

No potential conflict of interest relevant to this article was reported.

\section{REFERENCES}

1. Young JL Jr, Ward KC, Wingo PA, Howe $\mathrm{HL}$. The incidence of malignant noncarcinomas of the female breast. Cancer Causes Control 2004:15:313-9.

2. Bahrami A, Resetkova E, Ro JY, Ibanez JD, Ayala AG. Primary osteosarcoma of the breast: report of 2 cases. Arch Pathol Lab Med 2007;131:792-5.

3. Silver SA, Tavassoli FA. Primary osteogenic sarcoma of the breast: a clinicopathologic analysis of 50 cases. Am J Surg Pathol 1998;22:925-33.

4. Adem C, Reynolds C, Ingle JN, Nascimento AG. Primary breast sarcoma: clinicopathologic series from the Mayo Clinic and review of the literature. Br J Cancer 2004; 91:237-41.

5. Rakha EA, Tan PH, Shaaban A, Tse GM, Esteller FC, van Deurzen CH, et al. Do primary mammary osteosarcoma and chondrosarcoma exist? A review of a large multi-institutional series of malignant matrix-producing breast tumours. Breast 2013;22:13-8.

6. Kaufman MW, Marti JR, Gallager HS, Hoehn JL. Carcinoma of the breast with pseudosarcomatous metaplasia. Cancer 1984:53:1908-17.

7. Remadi S, Doussis-Anagnostopoulu I, Mac Gee W. Primary osteosarcoma of the breast. Pathol Res Pract 1995;191:471-4; discussion 475-7.

8. Jakovljevic SD, Spasic MB, Milosavljevic MZ, Azanjac GL, Protrka ZM, Radovanovic DM, et al. Pure primary osteosarcoma of the breast: a case report. Eur J Gynaecol Oncol 2013:34:476-9.

9. Conde DM, Morais LC, Pacheco CF, Ferreira RB, Sousa-e-Silva EP, Nunes AR, et al. Primary osteosarcoma of the breast: pathological and imaging findings. Rev Assoc Med Bras (1992) 2015;61:497-9.

10. Brustugun OT, Reed W, Poulsen JP, Bruland OS. Primary osteosarcoma of the breast. Acta Oncol 2005:44:767-70. 